\title{
Crisis política en Filipinas
}

$\mathrm{L}$ a todavía incipiente democracia filipina enfrenta un período difícil: el inminente juicio político a su primer mandatario, José Estrada. La cámara baja acusó, el pasado 12 de noviembre, al jefe del ejecutivo, de corrupción y de haber aceptado sobornos, por lo que el senado iniciará el primer juicio de esta naturaleza en la historia del país asiático. Aunque el destino del actor convertido en presidente está lejos de ser decidido, pues todavía cuenta con un estrecha mayoría entre los 22 senadores que emitirán el fallo final, lo más probable es que termine como el ex presidente brasileño Fernando Collor de Mello - y no la del todavía mandatario estadounidense Bill Clinton-. Y es que, como en el caso del sudamericano, el del filipino demuestra que la falta de oficio se paga en la política.

El problema no es simplemente que Estrada haya seguido con las juergas en centros nocturnos (a que estaba acostumbrado cuando todavía pertenecía a la farándula), sino la corrupción e ineficiencia que han caracterizado a su administración. Electo a mediados de 1998 para un término de seis años, Estrada es acusado de aceptar sobornos de una especie de sindicato de centros nocturnos ilegales, así como de haber desviado impuestos provenientes del consumo de tabaco; todo por un monto de 11 millones de dólares. Además, la presente administración filipina se ha caracterizado por el favoritismo hacia los amigos del primer mandatario. Así, el gobierno de Estrada retiró los derechos de aterrizaje a

* Investigador del Departamento de Estudios del Pacífico de la Universidad de Guadalajara. una aerolínea taiwanesa, lo cual causalmente benefició a una aerolínea doméstica, propiedad de un amigo cercano del presidente, Lucio Tan.

Para complicar aún más las cosas, la administración Estrada ha congelado los programas de reforma económica iniciados por sus dos antecesores: Corazón Aquino y Fidel Ramos. Tanto el programa de privatizaciones como el de reformas para incrementar la competencia económica prácticamente se han detenido en el presente gobierno. Aunque este cambio de política ha contado con el apoyo de sus beneficiarios -muchos de ellos allegados de Estrada-, tanto los grupos políticos de los ex presidentes que iniciaron el programa de liberalización económica, como los inversionistas extranjeros no han visto con buenos ojo este viraje. No es de sorprender, pues, que Corazón Aquino esté participando activamente en la organización de las multitudinarias marchas que demandan la renuncia de Estrada (por ejemplo, más de 100000 personas participa-ron en las que tuvieron lugar luego de que la cámara de diputados decidiera que el Senado inicie el juicio político).

De lograr su objetivo los opositores del presidente filipino, el poder pasaría a manos de la actual vicepresidenta, Gloria Arroyo. Lo interesante de este escenario es que la vicepresidenta no es simplemente la sombra del actual mandatario. Al contrario: además de ser una de las políticas más experimentadas y con más presencia en su país, Arroyo es franca adversaria de Estrada. De acuerdo con el 
peculiar sistema electoral filipino, la vicepresidenta, perteneciente a un partido de oposición, fue electa directamente para su cargo. Así, Arroyo tiene un fuerte mandato propio. Pero ella, hija de un ex presidente y ex compañera de Bill Clinton en la Universidad de Georgetown, tiene también ideas propias.

Aun antes de que inicie el juicio político a su todavía superior, Arroyo ha empezado ya a delinear lo que sería su "agenda nacional alternativa" para sus primeros 100 días de gobierno. Entre sus planes destacan el de revitalizar el sistema de partidos en su país y el de proseguir con el programa de liberalización económica que la actual administración interrumpió. Además, es de esperarse que, de asumir la primera magistratura, adopte una posición más conciliadora en el enfrentamiento militar en la provincia de Mindanao, en la cual ella vivió cuando era niña, con el grupo separatista Frente de Liberación Moro Islámico.

El jefe de asesores de la vicepresidenta para cuestiones de seguridad es el general Villa, el cual fungió como secretario de defensa en la administración de Ramos. En esa responsabilidad, el general Villa jugó un papel fundamental en el proceso que llevó a la firma (en 1996) de un acuerdo de paz entre el gobierno de Ramos y el Frente de Liberación Nacional Moro. Villa ha indicado que él está a favor de una negociación similar con el Frente de Liberación Moro Islámico.

De llegar a la presidencia por la defenestración de Estrada, Arroyo tendría la posibilidad de permanecer nueve años en el poder, pues aunque el presidente no puede reelegirse, ella no habría llegado a la primera magistratura (que no a la vicepresidencia) por voto popular, por lo que las leyes le permitirían postularse como candidata para el siguiente período. Así, parece que todo está dado para que, por la vía institucional, las Filipinas dejen atrás la oscura etapa que la administración Estrada ha representado para el país. 